\title{
O profissional de Pedagogia em espaços não escolares: uma análise preliminar da produção científica
}

\author{
Pedagogy professionals in non-school spaces: a preliminary \\ analysis of scientific production
}

\author{
Nilzilene Imaculada Lucindo \\ Doutoranda em Educação \\ Professora da Faculdade de Educação/Campus BH \\ Universidade do Estado de Minas Gerais, Belo Horizonte, MG, Brasil \\ nilzilenelucindo@yahoo.com.br \\ Célia Maria Fernandes Nunes \\ Doutora em Educação \\ Professora do Programa de Pós-Graduação em Educação \\ Universidade Federal de Ouro Preto, MG, Brasil \\ cmfnunes1@gmail.com \\ Regina Magna Bonifácio de Araújo \\ Doutora em Educação \\ Professora do Programa de Pós-Graduação em Educação \\ Universidade Federal de Ouro Preto, MG, Brasil \\ regina.araujo@ufop.edu.br
}

\begin{abstract}
Resumo: O presente artigo aborda a produção cientifica acerca do profissional de Pedagogia em espaços não escolares, constituída a partir da leitura dos resumos de dissertações e teses defendidas no Brasil entre 2006 a 2018 e explicita dados relativos ao objeto de estudo, finalidade das pesquisas; desenhos; sujeitos e locus investigados, além de apresentar algumas reflexões sobre o campo. Como resultados foram identificados 35 trabalhos, contudo, apurou-se que o número de pesquisas que investigam essa temática em nível de Doutorado e em algumas regiões brasileiras é incipiente, o que demanda adensar a produção desse campo. Apesar de serem numerosos os campos de atuação do pedagogo, o estudo revelou um descompasso entre o número de espaços não escolares existentes e o de investigações realizadas.
\end{abstract}

Palavras-chave: Estado do Conhecimento. Pedagogo. Espaços não escolares.

Abstract: This article addresses the scientific production about the Pedagogy professional in non-school spaces, constituted by reading the abstracts of dissertations and theses defended in Brazil between 2006 to 2018 and explains data related to the object of study, purpose of the research; drawings; investigated subjects and locus, besides presenting some reflections on the field. As a result, 35 papers were identified, however, it was found that the number of studies that investigate this topic at the Doctorate level and in some Brazilian regions is incipient, which demands to increase the production of this field. Although the pedagogue's fields of action are numerous, the study revealed a mismatch between the number of existing non-school spaces and the number of investigations carried out.

Keywords: State of Knowledge. Pedagogue. Non-school spaces. 


\section{Introdução}

A revisão bibliográfica é a fase inicial de todo processo investigatório, pois possibilita o conhecimento da produção científica de determinada área, revelando o foco dessas investigações, sua evolução e os aspectos que já foram abordados, bem como aqueles que demandam novas pesquisas. As pesquisas de caráter bibliográfico são denominadas por Ferreira (2002) de "estado da arte" ou "estado do conhecimento". Essa autora afirma que

Definidas como de caráter bibliográfico, elas parecem trazer em comum o desafio de mapear e de discutir uma certa produção acadêmica em diferentes campos do conhecimento, tentando responder que aspectos e dimensões vêm sendo destacados e privilegiados em diferentes épocas e lugares, de que formas e em que condições têm sido produzidas certas dissertações de mestrado, teses de doutorado, publicações em periódicos e comunicações em anais de congressos e de seminários. Também são reconhecidas por realizarem uma metodologia de caráter inventariante e descritivo da produção acadêmica e científica sobre o tema que busca investigar, à luz de categorias e facetas que se caracterizam enquanto tais em cada trabalho e no conjunto deles, sob os quais o fenômeno passa a ser analisado. (FERREIRA, 2002, p.258)

$\mathrm{Na}$ visão de Romanowski e Ens (2006, p.37) “a realização de estados da arte possibilita a efetivação de balanço da pesquisa de uma determinada área” e o interesse por tais pesquisas "deriva da abrangência desses estudos para apontar caminhos que vêm sendo tomados e aspectos que são abordados em detrimento de outros” (p.38). Na percepção de Morosini (2015, p. 102) “a consulta, a sistematização e a análise do que foi produzido no seu campo disciplinar, em especial no país do pesquisador, são importantes para fundamentar o que será produzido numa tese ou dissertação qualificada".

Segundo Romanowski e Ens (2006), embora as pesquisas intituladas "estado da arte" e "estado do conhecimento" se aproximem ao elegerem um objetivo semelhante, elas apresentam uma distinção, se distanciando em função da abrangência das fontes de estudos empregadas. As pesquisas denominadas "estado da arte" são mais amplas e não se detém somente nos estudos dos resumos de dissertações e teses, elas agregam estudos sobre as produções em congressos e publicações em periódicos, ao passo que as pesquisas denominadas de "estado do conhecimento" privilegiam apenas um setor das publicações.

Entendimento diverso é apresentado por Morosini (2015) para quem o estado do conhecimento "é identificação, registro, categorização que levem à reflexão e síntese sobre a produção científica de uma determinada área, em um determinado espaço de tempo, congregando periódicos, teses, dissertações e livros sobre uma temática específica" (MOROSINI, 
2015, p. 102). Observa-se que Morosini (2015) denomina de "Estado do Conhecimento" o que Romanowski e Ens (2006) intitula de "Estado da Arte" e a diferença que perpassa os conceitos reside justamente na amplitude das fontes que são pesquisadas.

O texto que ora se apresenta trata-se de uma análise preliminar acerca do Estado do Conhecimento da produção científica relativa ao Profissional de Pedagogia em espaços não escolares. O corpus deste trabalho foi constituído a partir da leitura dos resumos de dissertações e teses defendidas no Brasil entre os anos de 2006 a 2018 e explicita dados referentes ao objeto de estudo, finalidade das pesquisas; desenhos; sujeitos e locus investigados, além apresentar algumas reflexões sobre o campo e, principalmente, contribuições para a pesquisa de Doutorado em fase inicial de desenvolvimento na Universidade Federal de Ouro Preto (UFOP).

A busca pelos trabalhos no catálogo de teses e dissertações disponibilizado pela Coordenação de Aperfeiçoamento de Pessoal de Nível Superior (CAPES) foi realizada em dois momentos, sendo o primeiro em fevereiro de $2017^{1}$ e o segundo ${ }^{2}$ em abril de 2019.

Desenvolvido, predominantemente, no portal da CAPES, o mapeamento buscou levantar as pesquisas de Mestrado e Doutorado que abordam a temática do pedagogo em espaços não escolares e, para tanto, utilizou como descritores as palavras-chave: pedagogo; atuação profissional; educação não formal; espaços não escolares. Essa busca permitiu o acesso a uma relação de diversas dissertações e teses, mas, como forma de delimitar o campo de investigação, o recorte estabelecido priorizou aquelas pesquisas concentradas na área de educação que se aproximavam do objeto em estudo: o pedagogo em espaços não escolares.

É relevante destacar que nem todos os trabalhos selecionados estavam disponíveis para download na plataforma da Capes. Dessa forma, foi necessário recorrer a outras bases como a Biblioteca Digital Brasileira de Teses e Dissertações (BDTD) e ao banco de dissertações e teses dos programas onde os trabalhos foram defendidos.

\section{A produção científica do campo em números}

Na base de dados da CAPES, no período de 2006 a 2018, acerca do profissional de Pedagogia que atua em espaços não escolares, foi identificado um total de 35 pesquisas defendidas, sendo 30 dissertações e 5 teses, conforme sintetizado no quadro 1. 


\section{Dialogia}

LUCINDO, Nilzilene Imaculada; NUNES, Célia Maria Fernandes; ARAÚJO, Regina Magna Bonifácio de. O profissional de Pedagogia em espaços não escolares: uma análise preliminar da produção científica

Quadro 1 - Pesquisas defendidas e consultadas

\begin{tabular}{|l|l|}
\hline \multicolumn{1}{|c|}{ Dissertações } & \multicolumn{1}{|c|}{ Teses } \\
\hline AQUINO (2011); & FALCO (2010); \\
ABRAL (2013); & FRISON (2006); \\
CHESINI (2015); & OLIVEIRA (2015); \\
COSTA (2014); & SEVERO (2015); \\
FERREIRA (2013); & \\
FIREMAN (2006); & \\
FREITAS (2012); & \\
LACERDA (2016); & \\
LAPADULA (2017); & \\
MACHADO (2014); & \\
MANDÚ (2013); & \\
MASCARENHAS (2011); & \\
MEIRELES (2011); & \\
MELO (2010); & \\
MENDES (2016); & \\
NASCIMENTO (2008); & \\
PEDROZA (2013); & \\
PEREIRA (2016); & \\
PEREIRA (2013); & \\
PRINCEPE (2010); & \\
PUCHALE (2016); & \\
RABELO (2014); & \\
RIBEIRO (2009); & \\
SANTOS (2009); & \\
SANTOS (2012); & \\
SANTOS (2014); & \\
SEVERO (2012); & \\
SILVA (2009); & \\
SOUZA (2015); & \\
SOUZA (2016). & \\
FOAt Elaborasa propra a pati dos dados coleta & \\
\end{tabular}

Fonte: Elaboração própria a partir dos dados coletados no Portal da CAPES.

As investigações também foram classificadas segundo o nível (Mestrado ou Doutorado) e por ano de defesa, conforme Gráfico 1. 
Gráfico 1 - Número de investigações por ano e nível

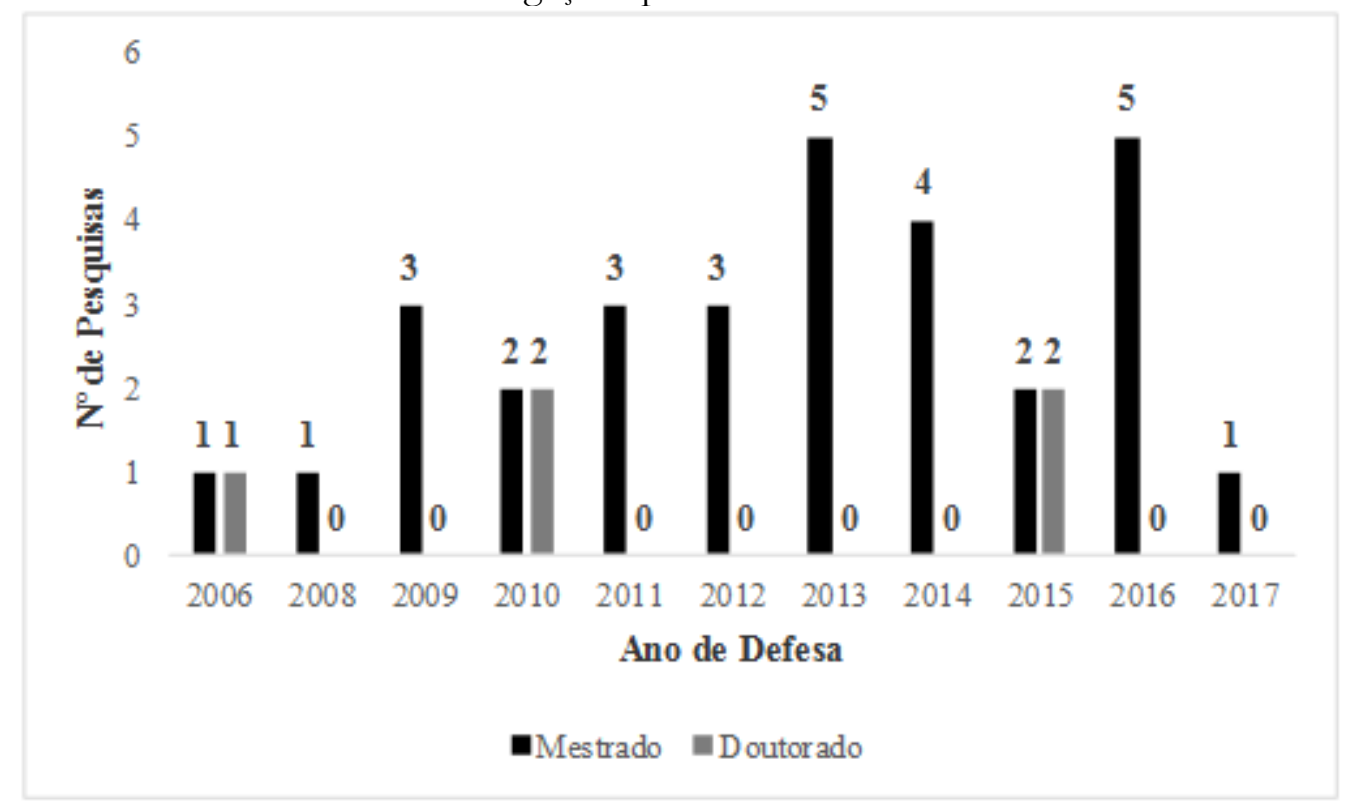

Fonte: Elaboração própria a partir dos dados coletados no Portal da CAPES.

Analisando o Quadro 1 constata-se que o número de estudos que tratam da temática pesquisada é maior nos cursos de Mestrado (85,7\%) em detrimento das investigações realizadas nos cursos de Doutorado (14,3\%). Esses dados demonstram que há uma regularidade nas investigações que discutem esse tema a partir de 2008, contudo, é imprescindível adensar a produção científica, sobretudo, em nível de Doutorado, pois foi constatada uma insuficiência de estudos nesse nível.

O Gráfico 1 indica que os anos com a maior concentração de estudos são os de 2013 e 2016, os quais totalizam 5 investigações de Mestrado desenvolvidas em cada ano. O quantitativo apresentado pode encontrar explicação em diversos fatores.

O primeiro fator a ser considerado trata-se da Resolução do Conselho Nacional de Educação CNE/CP n ${ }^{\circ}$ 01, de 15 de maio de 2006 (BRASIL, 2006) que instituiu as Diretrizes Curriculares Nacionais para o Curso de Graduação em Pedagogia, licenciatura. Essa Resolução determina que a docência é a base de formação do pedagogo, contudo, também menciona que "o egresso do curso de Pedagogia deverá estar apto a [...] trabalhar, em espaços escolares e não escolares" (BRASIL, 2006, p.2). Assim, a normativa legal indicou como campo de atuação do pedagogo tanto os espaços escolares quanto os espaços não escolares.

Oliveira (2015) menciona que campos de atuação profissional distintos do escolar não foram discutidos na sua formação e nem quando atuava como docente do curso de Pedagogia. Com base na afirmação dessa autora, um segundo aspecto que poderá justificar a tendência dos 
focos das pesquisas tem relação com as legislações anteriores que normatizavam o curso de Pedagogia e à própria origem do curso que, segundo Libâneo e Pimenta (2011), surgiu com o propósito de formar professores para atuar no Curso Normal e em funções específicas na escola e no sistema escolar. Ou seja, antes da atual diretriz, o foco mais evidenciado era o espaço escolar.

Um terceiro aspecto trata-se do campo de inserção profissional dos egressos desse curso. O estudo de Vargas (2016) demonstra que o principal campo de atuação do pedagogo tem sido o escolar. Logo, as pesquisas que enfocam o universo escolar superam o número de pesquisas que investigam a atuação desse profissional no espaço não escolar.

Como quarto fator que pode justificar o aumento das pesquisas acerca do pedagogo nos espaços não escolares, apresentamos os pressupostos de Gohn (2005); Libâneo (2010) e Severo (2015) acerca da diversidade de práticas educativas existentes na contemporaneidade. Talvez possa ser esse um dos elementos que também induziu a inclusão dos "espaços não escolares" no texto das diretrizes em vigor e ainda, o fator que mais contribuiu para alavancar a produção da área nos últimos anos. Ademais não podemos esquecer que em um curso que forma pedagogos, a pedagogia, ciência da educação, deve se constituir um conceito central na formação desses profissionais. Logo, "a pedagogia deve ter como um dos focos essenciais de seu trabalho o fazer educacional não só das escolas e de seus professores, mas das diversas instituições com possibilidades educativas" (FRANCO, 2008, p.79).

O levantamento apurou a produção acadêmica das Instituições de Ensino Superior (IES) por dependência administrativa, conforme pode ser observado na Tabela 1.

Tabela 1 - Número de pesquisas por dependência administrativa das IES

\begin{tabular}{ccc}
\hline Dependência Administrativa da IES & Mestrado & Doutorado \\
\hline Estadual & 8 & 1 \\
Municipal & 0 & 0 \\
Federal & 11 & 2 \\
Privada & 11 & 2 \\
Total & 30 & 5 \\
\hline
\end{tabular}

Fonte: Elaboração própria a partir dos dados coletados no Portal da CAPES.

De acordo com a Tabela 1, a produção é semelhante nas redes federal e privada, cada qual com 13 trabalhos.

O número de trabalhos produzidos por região também foi mapeado e pode ser observado na Tabela 2. 
Tabela 2 - Número de pesquisas por região

\begin{tabular}{ccc}
\hline Regiões & Mestrado & Doutorado \\
\hline Norte & 2 & 0 \\
Nordeste & 10 & 2 \\
Centro-Oeste & 2 & 0 \\
Sudeste & 10 & 0 \\
Sul & 6 & 3 \\
Total & $\mathbf{3 0}$ & $\mathbf{5}$ \\
\hline
\end{tabular}

Fonte: Elaboração própria a partir dos dados coletados no Portal da CAPES.

A Região que lidera a produção acerca da temática pesquisada foi a Nordeste (12), acompanhada pela Sudeste (10) e Sul (9), sendo que essa última lidera com as 3 pesquisas de Doutorado. A Norte e Centro-Oeste carecem de pesquisas em nível de Doutorado que tenham como objeto de estudo o pedagogo em espaços não escolares, assim como a Sudeste que, embora tenha desenvolvido 10 dissertações, ainda não conta com nenhuma tese. Esses dados podem ser tratados como indícios de que, especialmente, na região Norte e Centro-Oeste os espaços não escolares não têm se constituído um campo de inserção do pedagogo e/ou que o campo majoritário de atuação é o escolar. Podem também prenunciar que privilegia-se nos cursos de Pedagogia dessas regiões a docência e a atuação no espaço escolar. Uma última suposição é que o pedagogo em espaços não escolares ainda não se configurou como um objeto de interesse dos pesquisadores dessas regiões.

A esse respeito, Severo (2015) que tomou como sujeitos de pesquisa 38 pedagogos provenientes de 4 regiões brasileiras, exceto da Centro-Oeste, que detiveram, durante sua formação e/ou atuação profissional, experiência na educação não escolar (ENE), registra que "quando perguntados sobre experiências de contato com saberes e práticas em ENE durante o curso de Pedagogia, os participantes expressaram dados que confirmam a pouca relevância que esse campo possui no currículo do curso [...]” (SEVERO, 2015, p.189). Esses indícios ratificam o lugar que esse objeto de estudo ocupa na formação, na atuação e no âmbito da pesquisa.

A análise dos resumos evidenciou que, na maioria das investigações, o pedagogo que atua em espaços não escolares foi o objeto de estudo central. Após essa constatação, salienta-se o que os pesquisadores buscavam saber a respeito do principal objeto de estudo. Para facilitar essa compreensão, nove categorias foram estabelecidas. Assim, os pesquisadores buscavam saber em relação a atuação e o trabalho do pedagogo; as atribuições, as atividades, o papel e as funções desenvolvidas pelo pedagogo; a prática do pedagogo; a formação e as políticas de formação do pedagogo para atuar nesse campo; a autorregulação da aprendizagem presente na atuação do 
pedagogo; as representações sociais do pedagogo sobre seus espaços de atuação; os saberes dos pedagogos; as contribuições do pedagogo para os programas e projetos; a significação da Pedagogia para os formadores de pedagogos.

A partir da delimitação do objeto de estudo também foi possível identificar os distintos locus em que o pedagogo se insere e nos quais as pesquisas foram realizadas. Os sujeitos foram investigados na educação não formal em projetos educacionais que atendem a crianças e adolescentes; em centros de recreação; em bibliotecas; na educação especial; em contextos diversos como nas instituições não governamentais, governamentais, cooperativas, instituições ligadas ao comércio e às indústrias e sindicatos; em centros de atendimento socioeducativo de internação ao adolescente; nos presídios e no sistema prisional; na educação social realizada em diversos espaços não escolares; em escolas municipais abertas aos finais de semana para o desenvolvimento de projetos sociais; nas varas cíveis e criminais; em ambientes organizacionais; em instituições de abrigo e acolhimento; no contexto hospitalar; em unidades de saúde; de saúde mental e em associações aos portadores de câncer; nas secretarias municipais de assistência social; na associação de equoterapia; nos museus; no patrimônio histórico e em algumas IES formadoras.

A pesquisa de Lacerda (2016) mencionou pedagogos atuando em outros espaços não escolares em Belém, no Pará e Freitas (2012) relacionou os espaços que oferecem vagas para o pedagogo fora da área escolar no Estado do Pará. Pelo exposto pode-se concluir que o campo de atuação do pedagogo não se restringe ao espaço escolar e que há, conforme afirmou Severo (2015, p.33), uma “pluralização dos cenários de ação profissional do pedagogo”. Por conseguinte, se há pedagogos atuando em diferenciados espaços não escolares, se faz necessário o desenvolvimento de pesquisas que explorem essa formação e atuação.

O exame empreendido também possibilitou especificar quais espaços foram os mais explorados nas investigações desenvolvidas no período entre 2006 e 2018. O resultado segue explicitado na Tabela 3. 
Tabela 3 - Espaços explorados

\begin{tabular}{cc}
\hline Espaços & Frequência \\
\hline $\begin{array}{c}\text { Contextos Diversos de Educação Social e Educação Não Formal } \\
\text { (Centro de Recreação, Biblioteca, Educação Especial, Casa Lar, }\end{array}$ & \\
Programas e Projetos) & 4 \\
Empresas & 4 \\
Fundação CASA, Penitenciária, Sistema Prisional & 4 \\
Secretaria Municipal de Assistência Social & 2 \\
Escolas Municipais (abertas aos finais de semana para & 1 \\
desenvolvimento de projetos sociais) & \\
Unidades de Saúde, Saúde Mental e Associação aos Portadores de & 2 \\
Câncer & 2 \\
Instituto de Acolhimento e Abrigo & 4 \\
Hospitais & 5 \\
Organizações Não Governamentais & 1 \\
Associação de Equoterapia & 2 \\
Museus / Patrimônio Histórico & 1 \\
Varas Cíveis e Criminais & 3 \\
Instituições de Ensino Superior (Formadora) & 35 \\
Total &
\end{tabular}

Fonte: Elaboração própria a partir dos dados coletados no Portal da CAPES.

Com base na tabela nota-se que em alguns estudos o autor apenas intitulou o locus investigado como espaço de educação não formal, instituição não escolar ou espaços não escolares. Acredita-se que isso se deve a pesquisas que trabalharam com mais de um sujeito e cada qual desses atuava em um espaço diferente. Esse fato inviabilizou uma caracterização mais precisa como a dos demais espaços que foram apresentados de forma mais específica. À vista disso, percebeu-se a necessidade de compreender quais espaços podem ser enquadrados como espaços de educação não formal e/ou espaços não escolares. O conceito também poderá ser melhor esclarecido com a leitura dos trabalhos de Ribeiro (2009), Santos (2014); Santos (2012); Cabral (2013); Ferreira (2013); Melo (2010); Aquino (2011); Pereira (2013); Príncepe (2010).

A tabela 3 retrata que os espaços mais explorados foram as organizações não governamentais; os espaços pertencentes à área da saúde que englobam os hospitais e demais unidades de saúde; os presídios e/ou centro de atendimento socioeducativo e as empresas.

De forma sintetizada foram objetivos estabelecidos para as investigações: identificar, analisar e refletir sobre a formação e a atuação dos pedagogos fora da instituição escolar; investigar como (re)configuram-se as identidades profissionais dos pedagogos a partir da inserção profissional na empresa; identificar as atribuições previstas nos documentos e na prática 
cotidiana; analisar a prática do pedagogo; analisar os saberes constituídos na formação inicial do pedagogo em experiência de educação não escolar e os saberes que utilizam; analisar as políticas de formação do pedagogo nos documentos oficiais que tratam das orientações para atuação desse profissional nos espaços não escolares; avaliar o papel do pedagogo na Educação Social; analisar as novas exigências profissionais de atuação do Pedagogo no espaço educativo para além do ensino regular; analisar as contribuições desses sujeitos na execução de políticas de assistência social; identificar as representações sociais de egressos, formadores e médicos sobre a atuação do pedagogo nesses espaços; identificar os fazeres e os saberes de pedagogos; investigar as necessidades formativas de educadores sociais que atuam em Organizações Não Governamental $(\mathrm{ONG})$; analisar e sistematizar indicadores para sua formação; compreender a educação não escolar como objeto de formação e práticas profissionais em Pedagogia; analisar os limites e as potencialidades dos pedagogos nas organizações não formais de ensino.

Em relação ao desenho, as pesquisas, em sua totalidade, fizeram uso da abordagem qualitativa. Quanto aos procedimentos técnicos, 19 estudos utilizaram a análise documental; 21 a pesquisa bibliográfica e 24 a pesquisa de campo. No caso da pesquisa documental, foram analisados os projetos políticos pedagógicos dos cursos investigados, as Diretrizes Curriculares de 2006, os projetos que os pedagogos coordenam nesses espaços e outros documentos alusivos ao universo de atuação dos sujeitos.

No tocante aos instrumentos de coleta de dados, a entrevista foi a mais utilizada, tendo seu uso se dado por 30 pesquisadores. Na maioria das pesquisas (26) foi utilizada a entrevista semiestruturada. O questionário fez parte de 15 estudos e 11 utilizaram a observação. Quanto ao tratamento dos dados, 11 pesquisadores fizeram uso da Análise de Conteúdo; 2 utilizaram a Análise do Discurso e outro fez uso do Programa QSR Nvivo 10.

Como pode ser verificado pela triagem, a abordagem qualitativa é a metodologia mais utilizada e indicada quando se busca a descrição de um fenômeno ou trazer à cena o sujeito, sua fala e seu universo de significados. Destaca-se ainda que os pesquisadores podem recorrer a uma diversidade de métodos e abordagens, mas esses devem possuir estreita relação com os objetivos estabelecidos na investigação, pois a metodologia adotada é decisiva para a obtenção dos resultados. O exame pormenorizado dos trabalhos de Lacerda (2016); Santos (2014); Tavares (2010); Ferreira (2013) que fizeram uso da entrevista e da observação como técnica de coleta de dados pode colaborar com novas reflexões acerca da construção desse objeto de estudo.

Majoritariamente, os pedagogos que atuavam nesses espaços fizeram parte dessas investigações, todavia, também participaram demais sujeitos com os quais os pedagogos 
interagem, tais como: chefias em geral (diretores, gestores, coordenadores); docentes, alunos, diretor de área, juízes, policial, aprisionados, egressos do sistema prisional (no caso de centro socioeducativo, presídios e penitenciárias); colaboradores (no caso de empresas); gestores e outros profissionais da equipe (no caso de ONGs); médicos (no caso de hospitais); assistentes sociais (no caso da Secretaria de Assistência Social); coordenadores de programas e projetos coordenados pelos pedagogos. Também foram sujeitos das pesquisas coordenadores de curso, professores formadores e egressos do curso de Pedagogia.

3 As contribuições da análise preliminar para a construção de investigações acerca da temática

O levantamento empreendido no Portal da CAPES permitiu o acesso a uma quantidade significativa de trabalhos que trazem contribuições para a investigação de Doutorado em fase inicial de desenvolvimento no Programa de Pós-Graduação em Educação da UFOP. A partir dele foi possível avançar na construção do objeto de estudo e acerca do conhecimento já produzido.

Embora este trabalho tenha sido elaborado a partir de resumos, é impossível não recorrer aos demais capítulos que integravam as dissertações e/ou teses. As leituras flutuantes realizadas contribuíram, principalmente, para a expansão do referencial teórico e metodológico.

A revisão bibliográfica permitiu, a partir da pesquisa de Santos (2009) ampliar as referências sobre a legislação relacionada aos presídios. O trabalho de Oliveira (2015) oferece contribuição ímpar ao trazer dados do cenário prisional pesquisado.

O estudo de Lacerda (2016); Rabelo (2014); Ferreira (2013); Aquino (2011) expandiram o conhecimento da literatura acerca das classes hospitalares, da trajetória do atendimento hospitalar, dos saberes do pedagogo nesses espaços, da humanização e escuta pediátrica, da criança hospitalizada, da brinquedoteca e a respeito de como descrever e caracterizar esse espaço.

Nascimento (2008) e Costa (2014) trataram da aprendizagem organizacional. Costa (2014) contribui ao aprofundar o conhecimento acerca das temáticas Pedagogia nas Organizações, Educação Corporativa, Gestão do Conhecimento, do Capital Intelectual e por Competências. Pereira (2013) apresentou o conceito de Educador Social e informou sobre a existência de cursos nessa área no Brasil.

Como ressaltaram Ferreira (2002); Romanowski e Ens (2006) e Morosini (2015) as pesquisas do tipo Estado do Conhecimento possibilitam uma visão ampla acerca da produção de determinada área do conhecimento e corrobora para o desenvolvimento de pesquisas futuras. Contudo, há que se ressaltar algumas limitações deste tipo de trabalho, como as causadas apenas 
pela leitura dos resumos. Algumas vezes, eles foram insuficientes para validar o entendimento, pois havia questões que não estavam claras. Alguns não apontavam a metodologia empregada e quais os instrumentos utilizados na coleta de dados. Se fez necessário acessar algumas partes do trabalho para compreender o contexto de sua realização, os sujeitos envolvidos e, até mesmo, qual era o objeto de estudo.

Conforme já destacado, os dados que compõem o corpus deste texto são preliminares e demandam uma leitura completa das dissertações e teses referenciadas, pois, a partir dessa podese ampliar a compreensão do estudo, expandir os referenciais bibliográficos e metodológicos, bem como relacionar peculiaridades da nossa investigação com a desses pesquisadores. Essa leitura na íntegra dos trabalhos possibilitará ainda a produção e a divulgação de novos conhecimentos contribuindo com os estudos da área.

Mesmo que embrionários, os dados aqui apresentados já colaboraram para ampliar o referencial teórico acerca do objeto de estudo. Foi possível constatar que tem sido poucos os estudos que investigam o pedagogo em espaços não escolares. Nas regiões norte e centro-oeste há um déficit e na região Sudeste não foram encontrados estudos acerca desse objeto em nível de Doutorado. Além disso, no cenário nacional, as investigações de Mestrado estão em maior número, expondo a necessidade de ampliar a produção do campo em nível de Doutorado. Podese concluir que há um descompasso entre o número de investigações que são realizadas e o de espaços no qual esses profissionais se inserem já que no Brasil há pedagogos exercendo atividade laboral em numerosos locus distintos do escolar.

Além da ampliação e da diversificação das práticas educativas e dos espaços que lidam com a educação ser uma realidade das sociedades contemporâneas, tal fenômeno carece de investigação. Expandir essa produção pode contribuir não só com a reorganização dos cursos de Pedagogia, mas para que a pedagogia alcance, de fato, o status de ciência da educação que conduz a formação desses profissionais e tem legitimidade para direcionar toda ação educativa que se faz presente em qualquer locus, seja ele escolar ou não escolar.

\footnotetext{
1 A pesquisa foi iniciada nessa época com a finalidade de realizar o Estado do Conhecimento para que esse subsidiasse a elaboração do Projeto visando o ingresso no Doutorado.

${ }^{2}$ Nesse último levantamento foram adotados os mesmos critérios de busca utilizados no primeiro.
} 


\section{Referências}

AQUINO, S. L. de. O pedagogo e seus espaços de atuação nas representações sociais de egressos do curso de pedagogia. 2011. 172 f. Dissertação (Mestrado em Educação) - Universidade Federal de Viçosa, Viçosa, 2011.

BRASIL. Conselho Nacional de Educação. Resolução no 1/2006 de 15 de maio de 2006. Institui Diretrizes Curriculares Nacionais para o Curso de Graduação em Pedagogia, licenciatura. Diário Oficial da União, Brasília, 16 maio 2006, Seção 1, p. 11. Disponível em:

<http://portal.mec.gov.br/cne/arquivos/pdf/rcp01_06.pdf>. Acesso em: 21 dez. 2013.

CABRAL, A. N. M. de A. Políticas de formação do pedagogo para atuação em espaços não escolares: o projeto político pedagógico da Autarquia Municipal do Ensino Superior de Goiana - PE. 2013. 128 p. Dissertação (Mestrado em Educação) - Centro de Educação, Universidade Federal da Paraíba, João Pessoa, 2013.

CHESINI, A. A. Pedagogos (as) em instituições de acolbimento: fazeres e saberes. 152 f. 2015.

Dissertação (Mestrado em Educação) -Universidade Federal do Paraná, Curitiba, 2015.

COSTA, S. L. F. O pedagogo em ambientes organizacionais: um novo prisma de atuação. 2014. 119 f. Dissertação (Mestrado em Educação) - Faculdade de Educação, Universidade do Estado do Rio Grande do Norte, Mossoró, 2014.

FALCO, A. M. C. O processo de formação do pedagogo para atuação em espaços não-escolares: em questão a Pedagogia Hospitalar. 2010. 245 f. Tese (Doutorado em Educação) - Universidade Estadual de Maringá, Maringá, 2010.

FERREIRA, H. P. de A. O pedagogo na associação de apoio aos portadores de câncer de Mossoró e região: práticas pedagógicas e os percursos formativos. 2013. 165 f. Dissertação (Mestrado em Educação) - Faculdade de Educação, Universidade do Estado do Rio Grande do Norte, Mossoró, 2013.

FERREIRA, N. S. de A. As pesquisas denominadas “estado da arte”. Educação \& Sociedade, São Paulo, ano 23, n. 79, p.257-272, ago. 2002.

FIREMAN, M. D. O trabalho do pedagogo na instituição não escolar. 2006. 116 f. Dissertação (Mestrado em Educação) - Centro de Educação, Universidade Federal do Pará, Belém, 2006.

FRANCO, M. A. S. Pedagogia como Ciência da Educação. 2ed. São

Paulo: Cortez, 2008.

FREITAS, R. C. F. O trabalho do pedagogo no tribunal de justiça do Pará: os desafios da inovação no exercício profissional. 2012. 142 f. Dissertação (Mestrado em Educação) - Instituto de Ciências da Educação, Universidade Federal de Alagoas, Alagoas, 2012.

FRISON, L. M. B. Auto-regulação da aprendiðagem: atuação do pedagogo em espaços não-escolares. 2006. 342 f. Tese (Doutorado em Educação) - Faculdade de Educação, Pontifícia Universidade Católica do Rio Grande do Sul, Porto Alegre, 2006. 
GOHN, M. da G. Educação não-formal e cultura política: impactos sobre o associativismo do terceiro setor. 3.ed. - São Paulo: Cortez, 2005.

LACERDA, F. B. O pedagogo no contexto hospitalar: para além da docência. 2016. 120 f. Dissertação (Mestrado) - Centro de Ciências Sociais e Educação, Universidade do Estado do Pará, Belém, 2016.

LAPADULA, M. F. Educação não-formal: um olhar sobre a formação e atuação de pedagogos (as) na Região dos Inconfidentes. 2017. 129 f. Dissertação (Mestrado em Educação) - Instituto de Ciências Humanas e Sociais, Universidade Federal de Ouro Preto, Mariana, 2017.

LIBÂNEO, J. C. Pedagogia e pedagogos, para quê? 12a ed. - São Paulo: Cortez, 2010.

LIBÂNEO, J. C.; PIMENTA, S. G. Formação de profissionais da educação: visão crítica e perspectiva de mudança. In: PIMENTA, S. G. (Org.) Pedagogia e Pedagogos: caminhos e perspectivas. 3. ed. São Paulo: Cortez, 2011. cap. 1, p. 15-61.

MACHADO, M. C. Z. Pedagogos nos espaços corporativos de educaşão: identidades profissionais em (re)definição. 2014. 133f. Dissertação (Mestrado) - Centro de Ciências Humanas e da Educação, Universidade do Estado de Santa Catarina, Florianópolis, 2014.

MANDÚ, T. M. C. Representações sociais do campo de atuação do pedagogo pelos estudantes de pedagogia. 2013. 158f. Dissertação (Mestrado) - Centro de Educação, Universidade Federal de Pernambuco, Recife, 2013.

MASCARENHAS, A. D. N. Percepcões de Médicos sobre o papel do pedagogo no trabalho com crianças hospitalizadas: o caso do Hospital das Clínicas da UFBA. 2011. 183 f. Dissertação (Mestrado) Faculdade de Educação, Universidade Federal da Bahia, Salvador, 2011.

MEIRELES, T. de F. W. O desafio do pedagogo nos espaços de educação não formal. 2011. $130 \mathrm{f}$. Dissertação (Mestrado) - Faculdade de Humanidades e Direito, Universidade Metodista de São Paulo, São Bernardo do Campo, 2011.

MELO, S. P. de. As responsabilidades do pedagogo em programas socioeducativos: novas exigências profissionais. 2010. 160 f. Dissertação (Mestrado) - Universidade Tuiuti do Paraná, Curitiba, 2010.

MENDES, M. C. Z. Educação em prisões: um estudo sobre o percurso histórico e o papel do pedagogo no Complexo Penitenciário de Guarapuava - Paraná. 2016. 221f. Dissertação (Mestrado) - Escola de Educação e Humanidades, Pontifícia Universidade Católica do Paraná, Curitiba, 2016.

MOROSINI, M. C. Estado de conhecimento e questões do campo científico. Revista Educaşão. Santa Maria, RS. v.40, n.1, p.101-116, jan./abr. 2015.

NASCIMENTO, L. A. Aprendizagens organizacional e auto-regulada: possibilidades para o desenvolvimento de pessoas em uma empresa. 2008. 174 f. Dissertação (Mestrado em Educação) - Faculdade de Educação, Pontifícia Universidade Católica do Rio Grande do Sul, Porto Alegre, 2008. 
OLIVEIRA, S. B. de. A formação do pedagogo para atuar no sistema penitenciário. 2015. 149 f. Tese (Doutorado em Educação) - Escola de Educação e Humanidades, Pontifícia Universidade Católica do Paraná, Curitiba, 2015.

PEDROZA, S. A atuação dos pedagogos nos espaços não formais de ensino. 2013.126 f. Dissertação (Mestrado em Educação) - Universidade Estácio de Sá, Rio de Janeiro, 2013.

PEREIRA, M. R. “Vem, vamos embora que esperar não é saber": experiências de educadores sociais em espaços de educação não formal no município de Mossoró, RN. 2016. 128 f. Dissertação (Mestrado em Educação) - Faculdade de Educação, Universidade do Estado do Rio Grande do Norte, Mossoró, 2016.

PEREIRA, P. R. A atuação do pedagogo em abrigos do município de Vitória/ES. 2013. 125 f. Dissertação (Mestrado em Educação) - Centro de Educação, Universidade Federal do Espírito Santo, Vitória, 2013.

PRÍNCEPE, L. M. Necessidades formativas de educadores que atuam em projetos de educação não-formal. 2010. 146 f. Dissertação (Mestrado) - Pontifícia Universidade Católica de São Paulo, São Paulo, 2010.

PUCHALE, S. M. O papel do pedagogo no contexto da educação corporativa. 2016.70 f. Dissertação (Mestrado) - Faculdade de Educação, Universidade Federal do Rio Grande do Sul, Porto Alegre, 2016.

RABELO, F. S. Educação não escolar e saberes docentes na formação do pedagogo: análise de uma experiência no espaço hospitalar. 2014. 184 f. Dissertação (Mestrado) - Centro de Educação, Universidade Estadual do Ceará, Fortaleza, 2014.

RIBEIRO, B. R. de S. A presença do pedagogo em patrimônio histórico no estuário Santos / Guarujá. 2009. 135 f. Dissertação (Mestrado) - Universidade Católica de Santos, Santos, 2009.

ROMANOWSKI, J. P.; ENS, R. T. As pesquisas denominadas do tipo "estado da arte" em educação. Diálogo Educ., Curitiba, v. 6, n.19, p.37-50, set./dez. 2006.

SANTOS, J. R. C. Políticas Públicas de Educação nos presídios: o papel do pedagogo em novos espaços como agente de transformação social. 2009. 156 f. Dissertação (Mestrado) - Universidade Católica de Brasília, Brasília, 2009.

SANTOS, P. F. B. dos. Educação Não Formal e Equoterapia: o galope do educador na arena da terapia. 2012. 120 f. Dissertação de Mestrado em Educação - Centro Universitário Salesiano de São Paulo, Americana, 2012.

SANTOS, S. S. dos. O pedagogo e os espaços educativos não formais: conhecendo as organizações não governamentais (ONG) de Paranaíba - MS. 2014. 124 f. Dissertação (Mestrado em Educação) Unidade Universitária de Paranaíba, Universidade Estadual de Mato Grosso do Sul, Paranaíba, 2014. 
SEVERO, J. L. R. de L. A significação da Pedagogia: discurso curricular, representações sociais e perspectivas de ensino na formação inicial de pedagogos. 2012. 195 f. Dissertação (Mestrado em Educação) - Centro de Educação, Universidade Federal da Paraíba, João Pessoa, 2012.

SEVERO, J. L. R. de L. Pedagogia e educação não escolar no Brasil: crítica epistemológica, formativa e profissional. 2015. 265 f. Tese (Doutorado em Educação) - Centro de Educação, Universidade Federal da Paraíba, João Pessoa, 2015.

SILVA, T. de J. A. da. A contribuição do Pedagogo em espaços fora da escola. 2009. 111 f. Dissertação (Mestrado em Educação) - Universidade Federal do Maranhão, São Luís, 2009.

SOUZA, A. S. de. Atribuições profissionais de pedagogos da Fundação Casa/SP: entre o prescrito e as práticas cotidianas. 2015. 178 f. Dissertação (Mestrado) - Universidade Cidade de São Paulo, São Paulo, 2015.

SOUZA, R. do N. de. O pedagogo e os espaços não escolares: a atuação nos museus. $2016.121 \mathrm{f}$.

Dissertação (Mestrado) - Departamento de Educação, Pontifícia Universidade Católica do Rio de Janeiro, Rio de Janeiro, 2016.

TAVARES, A. M. B. do N. O pedagogo como agente de transformação social para além dos muros escolares. 2010. 263 f. Tese (Doutorado em Educação) - Centro de Ciências Sociais Aplicadas, Universidade Federal do Rio Grande do Norte, Natal, 2010.

VARGAS, M. de L. F. Formação e inserção profissional do pedagogo: o panorama histórico desta carreira e os egressos do curso de Pedagogia presencial da Faculdade de Educação da UFMG. 2016. 297 f. Tese (Doutorado em Educação) - Faculdade de Educação, Universidade Federal de Minas Gerais, Belo Horizonte, 2016.

Recebido em: 21 fev. 2020 / Aprovado em: 15 abr. 2020

Cite como (ABNT NBR 6023:2018)

LUCINDO, Nilzilene Imaculada; NUNES, Célia Maria Fernandes; ARAÚJO, Regina Magna Bonifácio de. O profissional de Pedagogia em espaços não escolares: uma análise preliminar da produção científica. Dialogia, São Paulo, n. 34, p. 66-81, jan./abr. 2020. Disponível em: https://doi.org/10.5585/Dialogia.N34.16716. 